by tumour cells or local changes in the concentration of mucopolysaccharides and inorganic ions in the matrix have also been suggested. Histological changes are usually not seen in salivary tissue following low dose radiation exposure. However, TRC deposition may be a more subtle indication of damage following higher doses of irradiation. Other local and possibly systemic factors might also be expected to contribute. The focal distribution of crystalloids in this case might suggest that local variables within an individual tumour may be important, in addition to differences between left and right sides. The precise details of any mechanism, however, remain obscure and purely speculative.

In conclusion, these findings provide circumstantial evidence to support the hypothesis that deposition of TRCs in salivary neoplasms is influenced more by local than by systemic factors. Furthermore, it is proposed that irradiation of the head and neck may be one predisposing factor in TRC formation, an observation that has not previously been made, and that crystalloid deposition may be a subtle reflection of radiation induced damage in some cases.
The authors thank Mr B Sims for his technical advice and assistance.

1 Thomas K, Hutt MSR. Tyrosine crystals in salivary gland tumours. 7 Clin Pathol 1981;34:1003-5.

2 Gnepp DR, Schroeder W, Heffner D. Synchronous tumours arising in a single major salivary gland. Cancer 1989;63:1219-24.

3 Auclair PL, Ellis GL, Gnepp DR, Wenig BM, Janney CG. Salivary gland neoplasms: general considerations. In: Ellis GL, Auclair PL, Gnepp DR, eds. Surgical pathology of the salivary glands. Philadelphia: WB Saunders, 1991 135-64.

4 Valente PT, Hoober JK, Phillips SJ. Tyrosine-rich crystalloids in pleomorphic adenoma: SEM findings and partial biochemical characterization. Ultrastruct Pathol 1988;12:613-20.

5 Humphrey PA, Ingram P, Tucker A. Crystalloids in salivary gland pleomorphic adenomas. Arch Pathol Lab Med vary gland pleom

6 Campbell WG, Priest RE, Weathers DR. Characterization of two types of crystalloids in pleomorphic adenomas of minor salivary glands. A light microscopic, electron microscopic and histochemical study. Am $\mathcal{F}$ Pathol 1985;118:194-202.

7 Pearse AGE. Proteins, peptides and amino acids. In (ed.), Vol. 2 Histochemistry, theoretical and applied. 4th edn. Edinburgh: Churchill Livingstone, 1985:441-537.

8 Preston-Martin S, Thomas DC White SC Cohen D. Prior exposure to medical and dental X-rays related to tumours of the parotid gland. $7 N C I$ 1990;80:943-9.

9 Bottles K, Ferrell LD, Miller TR. Tyrosine crystals in fine needle aspirates of a pleomorphic adenoma of the needle aspirates of a pleomorphic ad

10 Gould AR, Van Arsdall LR, Hinkle SJ, Harris WR Tyrosine-rich crystalloids in adenoid cystic carcinoma: histochemical and ultrastructural observations. $f$ Oral Pathol 1983;12:478-90.

\title{
CD4+ lymphocytopenia due to common variable immunodeficiency mimicking AIDS
}

\author{
R S Kaczmarski, A D B Webster, J Moxham, F Davison, S Sutherland, G J Mufti
}

\author{
Department of \\ Haematological \\ Medicine, King's \\ College School of \\ Medicine and \\ Dentistry, Denmark \\ Hill, London SE5 8RX \\ R S Kaczmarski \\ G J Mufti \\ Department of \\ Thoracic Medicine \\ J Moxham \\ Immunodeficiency \\ Research Group, \\ CRC, Northwick Park \\ Hospital, Harrow, \\ Middlesex \\ A D B Webster \\ Department of \\ Virology, Dulwich \\ Hospital, London \\ F Davison \\ S Sutherland \\ Correspondence to: \\ Dr G J Mufti

\begin{abstract}
There are an increasing number of published reports of patients with acquired immunodeficiency without evidence of HIV infection, who have been labelled as having "idiopathic CD4+ lymphocytopenia". The case is reported here of a young man who presented with Pneumocystis carinii pneumonia (PCP), CD4+ lymphopenia, and hypogammaglobulinaemia attributable to common variable immunodeficiency (CVID). The presentation of this condition, with many of the clinical and laboratory features of AIDS, highlights CVID as a diagnosis to be considered in the differential diagnosis of CD4 + lymphocytopenia.
\end{abstract}

(F Clin Pathol 1994;47:364-366)

Recent reports have described cases of acquired immunodeficiency without evidence of infection by HIV. However, other diag- noses can mimic the clinical characteristics of AIDS and must not be overlooked. A case of Pneumocystis carinii pneumonia (PCP) is reported here in a young, single man who presented with weight loss, generalised lymphadenopathy, and lymphopenia, and who was persistently HIV negative.

\section{Case report}

A previously fit 37 year old man presented in October 1989 with a two month history of pruritis, night sweats, and cough. He was unmarried, heterosexual, and denied any homosexual contact, drug abuse, or travel overseas. On examination he had bilateral axillary and supraclavicular lymphadenopathy and hepatosplenomegaly. He declined further investigation. Six months later he returned with symptoms of anorexia, $20 \mathrm{~kg}$ weight loss, productive cough, and breathlessness. He was cachectic, febrile $\left(38^{\circ} \mathrm{C}\right)$, tachypnoeic, and had bilateral inguinal lymphadenopathy. Chest examination showed bilateral crackles 
$T$ cell subsets and immunoglobulin levels at presentation and during steroid treatment and immunoglobulin therapy

\begin{tabular}{lllllc}
\hline Date & $\begin{array}{l}C D 4 \\
(775-1385 \\
\left.\times 10^{6} / l\right)^{*}\end{array}$ & $\begin{array}{l}\text { CD8 } \\
(390-785 \\
\left.\times 10^{6} / l\right)\end{array}$ & $\begin{array}{l}\text { IgG } \\
(5-16 \\
g / l)\end{array}$ & $\begin{array}{l}\text { IgA } \\
(1 \cdot 2-4 \cdot 5 \\
g / l)\end{array}$ & $\begin{array}{l}\text { IgM } \\
(0 \cdot 47-2 \cdot 2 \\
g / l)\end{array}$ \\
\hline 10.5 .90 & 11 & 227 & $<3.54$ & 0.37 & 0.58 \\
$23.5 .90 \dagger$ & - & - & 3.54 & $<0.27$ & $<0.30$ \\
$6.6 .90+\ddagger$ & 914 & 291 & 6.48 & 0.62 & 0.93 \\
10.12 .90 & 309 & 310 & 6.57 & 0.61 & 0.47 \\
12.8 .91 & 52 & 62 & 3.99 & 0.38 & 0.24 \\
$24.9 .91 \oint$ & - & - & 4.62 & 0.56 & 0.38 \\
$28.1 .92 \oint$ & 220 & 110 & - & - & 0.43 \\
$11.5 .92 \oint$ & - & - & 8.33 & 0.43 & 0.44 \\
$25.9 .92 \oint$ & 51 & 83 & 6.98 & 0.42 & 0.51 \\
$4.5 .93 \$$ & - & - & 6.79 & 0.42 & 0.32 \\
\hline
\end{tabular}

*Normal ranges in parentheses

tPrednisolone for acute PCP

$¥$ Prednisolone for acute PCP

ÍIntravenous immunoglobulin replacement, ciprofloxacin, and prednisolone

and wheezes. Investigations showed a haemoglobin of $14 \mathrm{~g} / 1$, white cell count of $10 \cdot 2 \times 10^{9} / 1$ (neutrophils $9 \cdot 4 \times 10^{7} / 1$, lymphocytes $0.6 \times 10^{9} / 1$, monocytes $0.2 \times 10^{9} / 1$ ), and platelets of $332 \times 10^{9} / 1$. Urea and electrolytes were normal. Liver function tests showed total protein $43 \mathrm{~g} / \mathrm{l}$, albumin $25 \mathrm{~g} / \mathrm{l}$, bilirubin $6 \mathrm{mmol} / 1$ (normal range 3-20), alkaline phosphatase $252 \mathrm{IU} / 1$ (normal range 30-120), aspartate aminotransferase $41 \mathrm{IU} / 1$ (normal range 10-50), and gamma glutamyl transferase $50 \mathrm{IU} / 1$ (normal range 5-55). Chest $x$-ray pictures and computerised tomography (CT) scans showed bilateral patchy consolidation, pleural effusions, and hilar and mediastinal lymphadenopathy. A lymph node biopsy specimen, bone marrow aspirate, and trephine biopsy specimen showed reactive changes only. He did not respond to broad spectrum antibiotics. A lung biopsy was performed and the histology showed florid PCP.

In view of the persistent lymphopenia HIV infection was thought likely, although the patient denied any history of known risk factors. Lymphocyte subsets showed a sharp reduction in $\mathrm{CD} 4+\left(11 \times 10^{6} / 1\right)$ and $\mathrm{CD} 8+$ $\left(227 \times 10^{6} / 1\right) \quad T$ cells with a reversed CD4:CD8 ratio (table). Tests for HIV 1 and 2 antibodies and p24 antigen in serum, and polymerase chain reaction (PCR) amplification for HIV env and gag sequences in circulating mononuclear cells were negative on two occasions. The patient was treated with high dose intravenous co-trimoxazole $(120 \mathrm{mg} / \mathrm{kg} /$ day) and prednisolone $40 \mathrm{mg}$ daily, reducing over four weeks. The table shows the results of immunological tests, including $\mathrm{T}$ cell subsets (CD4, CD8) and immunoglobulin concentrations: hypogammaglobulinaemia was noted during treatment of PCP, and the patient was given a single dose of intravenous immunoglobulin. The PCP resolved and he was discharged in June 1990: CD4, CD8 counts, and immunoglobulin concentrations had improved (table). All medication was discontinued on follow up six weeks later.

The patient presented again in August 1991, with a swollen left leg and an ulcerating lymph node mass in the left groin. Hard, purple nodules had appeared over his trunk. A skin biopsy specimen showed chronic inflammatory changes, with no evidence of Kaposi's sarcoma, lymphoma, or other infiltrating processes. Lymphopenia persisted and once again hypogammaglobulinaemia was noted (table). Serological tests for HIV 1 and 2 and PCR for HIV remained negative, and antibody to HTLV-I was not detected. $\mathrm{He}$ declined further investigations, but five months later complained of further weight loss and a large suppurating ulcer in the left groin. However, the skin nodules had regressed, leaving discoloured, indurated skin. The lymphadenopathy and hepatosplenomegaly were unchanged. $\mathrm{He}$ was receiving no medication.

Computed tomograms showed pretracheal lymph nodes in addition to previous changes. A repeat skin biopsy and bone marrow examination were unchanged; but a lymph node biopsy specimen showed non-caseating granulomata with absence of germinal centres. Immunocytochemistry was negative for CD20 (Pan-B), with strongly positive CD45 RA ( $T$ cell, natural killer cell). Special stains for mycobacteria and fungi were negative. The appearances were those of a B cell immunodeficiency with granulomatous reaction, consistent with the diagnosis of common variable immunodeficiency (CVID).

The patient was given regular intravenous immunoglobulin replacement treatment $(200 \mathrm{mg} / \mathrm{kg}$ every two weeks) in August 1991. In view of the substantial granulomatous reactions affecting lymph nodes, skin, liver, and spleen, he was treated with prednisolone $10 \mathrm{mg}$ daily. He also took ciprofloxacin $500 \mathrm{mg}$ twice a day and inhaled pentamidine for PCP prophylaxis. By September 1992, the groin ulcer had healed completely; lymphadenopathy, hepatosplenomegaly, and pleural effusions had resolved. At the time of writing, the patient continues to take prednisolone and immunoglobulin therapy which maintains IgG concentrations in the normal range; but IgA and IgM remain low (table). He is well and has not had any further infective episodes.

\section{Discussion}

This case illustrates how the presentation of CVID can be mistaken for HIV infection. CVID is a heterogeneous disease which can present at any age with a wide range of symptoms. Typically, patients present in childhood or early adulthood with recurrent bacterial infections. There may or may not be a family history. Patients also have an increased incidence of opportunistic viral and fungal infections and an increased risk of developing malignancy. ${ }^{1-3} \mathrm{~A}$ significant number develop non-caseating granulomata, lymphoid hyperplasia, and splenomegaly. ${ }^{4}$ Although this patient had pronounced CD8 + neutropenia, this is unusual in CVID ${ }^{5}$; an increase in suppressor $\mathrm{T}$ cells, which block $\mathrm{B}$ cell differentiation, is thought to have a role in the pathophysiology of CVID. Treatment with immunoglobulin replacement and prophylactic antibiotics usually leads to substantial clinical improvement. ${ }^{2}$ PCP prophylaxis is not 
routinely given in these cases, unless there is a history. Intravenous immunoglobulin and antibiotics alone have no effect on the granulomatous lesions seen in these patients; but this case illustrates the benefit of steroids, which have been effective in other cases with severe granulomatous reactions (A D B Webster, personal observation).

A number of features in this case differentiate it from HIV infection. Although HIV antibody and p24 antigen tests may be negative in early disease, ${ }^{6}$ in HIV infection they are unlikely to remain negative when the tests are performed several months apart. Furthermore, gene amplification by PCR for the HIV genome has been shown to detect HIV in these "seronegative" cases.7 Primary HIV infection can cause a transient lymphopenia and lymphadenopathy. ${ }^{89}$ This was unlikely in this patient, however, as he presented with persistent generalised lymphadenopathy (PGL) and an opportunistic infection, features which are consistent with advanced HIV disease, when serological tests should detect HIV and the CD4 + count would be consistently low. Lymph node biopsy specimens in primary HIV infection show a normal pattern of germinal centre, and in PGL there is follicular hyperplasia. ${ }^{10} \mathrm{With}$ progressive disease the follicles atrophy and fibrose. The absence of germinal centres in this case is consistent with the $B$ cell immunodeficiency in CVID.

Immunoglobulin and $T$ cell counts can show considerable variation in CVID. This case illustrates this (table), when on some occasions $T$ cell and immunoglobulin subsets fell within the normal range. This can make the diagnosis of CVID difficult and illustrates the value of serial measurements. Conversely, in HIV infection there is a progressive decline in $\mathrm{CD} 4+$ counts, with temporary improvement in $\mathrm{CD} 4+$ counts only as a result of antiretroviral treatments using zidovudine (AZT), dideoxyinosine (ddI), or dideoxycytidine (ddC). HIV infection is also commonly associated with hypergammaglobulinaemia as a result of chronic immune stimulation by HIV and opportunistic pathogens, and the action of $B$ cell active cytokines, particularly interleukin-6. ${ }^{11}$ This is also reflected in the plasmacytosis frequently seen in bone marrow aspirates and lymph node biopsy specimens.

In conclusion, there are many overlapping clinical and laboratory features of HIV infection and CVID. In view of recent reports of "HIV negative AIDS", 12 this case illustrates the importance of considering CVID in the differential diagnosis of patients presenting with opportunistic or atypical infections and who are HIV negative.

1 Primary immunodeficiency diseases. Report of a World Health Organization sponsored meeting. Immunodefic Rev 1989;1:173-205.

2 Asherson GL, Webster ADB. Diagnosis and treatment of immunodeficiency disease. Edinburgh: Blackwell Scientific, 1980.

3 Hermans PE, Diaz-Buxo JA, Stobo JD. Idiopathic late onset immunoglobulin deficiency. Clinical observation in 50 patients. $A m \mathcal{F}$ Med 1976;61:221-37.

4 Davis SD, Eidelman S, Loop JW. Nodular lymphoid hyperplasia of the small intestine and sarcoidosis. Arch Intern Med 1970;126:668-72.

5 Spickett GP, Matamoros N, Farrant J. Lymphocyte surface phenotype in common variable immunodeficiency. Dis Markers 1992;10:67-80.

6 Imagawa DT, Lee MH, Wolinsky SM, et al. Human immunodeficiency virus type 1 infection in homosexual men who remain seronegative for prolonged periods. $N$ Engl $\mathcal{F}$ Med 1989;320:1458-62.

7 Wolinsky SM, Rinaldo CR, Kwok S, et al. Human immunodeficiency virus type 1 (HIV-1) infection a median of 18 months before a diagnostic western blot. Evidence from a cohort of homosexual men. Ann Intern Med 1989;111:961-72.

8 Cooper DA, Tindall B, Wilson B, Imrie AA, Penny R. Characterization of T-lymphocyte responses during primary HIV infection. F Infect Dis 1988;157:889-96.

9 Tindall B, Barker S, Donovan B, et al. Characterization of the acute illness associated with human immunodeficiency virus infection. Arch Int Med 1988;148:945-9.

10 Meyer P, Yanagihara ET, Parker JW, Lukes RJ. A distinctive follicular hyperplasia in the acquired immunodefitive follicular hyperplasia in the acquired immunodefiCiency syndrome and

11 Birx DL, Redfield RR, Tencer $\mathrm{K}$, et al. Induction of interleukin-6 during human immunodeficiency virus infection. Blood 1990;76:2303-10.

12 Laurence J, Siegal FP, Schattner E, Gelman IH, Morse S. Acquired immunodeficiency without evidence of infection with human immunodeficiency virus types 1 and 2 . Lancet 1992;340:273-4. 